\title{
Review of Control Strategies for Active Power Filters
}

\author{
Sneha Sanjay Nirmale ${ }^{1}$, Sangeeta Mahaddalkar ${ }^{2}$ \\ PG Student, Department of Electrical and Electronics, Goa College of Engineering, Ponda, India ${ }^{1}$ \\ Professor, Department of Electrical and Electronics, Goa College of Engineering, Ponda, India ${ }^{2}$
}

\begin{abstract}
In present days electricity has become non-separable from human life. Every sphere of human life is dependent on some or other equipment/machine in households, hospitals, industry etc. The consumers have different load patterns such as non-linear loads, switching etc. Such utility pattern results in harmonic generation and reactive power disturbances in the distribution system. The harmonics and reactive power cause a number of undesirable effects such as malfunction in sensitive equipment, over voltage by resonance, increased heat in conductor, harmonic voltage drop across the network impedance and thereby affects other customer loads connected at Point of Common Coupling (PCC). These undesirable effects are overcome to a great extent by deploying Active Power Filters (APF) at PCC. The power quality of a Distribution System can be improved by eliminating harmonics and disturbances due to reactive power. This is achieved by injecting required amount of compensating current to cancel out the harmonics and power disturbances and restore sinusoidal nature of voltage and current waveforms. This improves the power quality and helps protect the sensitive loads from malfunction thereby preventing damage. This paper presents a comprehensive review of Active Power filter configurations, their control strategies and the performance evaluation metrics such as Total Harmonic Distortion (THD) for different control strategies.
\end{abstract}

Keywords: Point of Common Coupling (PCC), Active Power Filters (APF), Total Harmonic Distortion (THD).

\section{INTRODUCTION}

In recent years focus have been given on the "electrical Active power filters acting as an ideal current source and power quality" i.e. degradation of voltage and current due injecting proper harmonic currents into the AC side can to harmonics, low power factor etc. The distribution solve the problem of the load current distortion, resulting system is a vital connection between generation and in a "clean" sinusoidal supply current. The modern power utilization of electrical power at rated amplitude and electronics provide suitable topology to mitigate the power frequency. Non-linear loads result in drawing distorted quality problems. The typical configuration of a shunt current from the electrical power systems due to active power filter is shown in Figure 1. A shunt active degradation of voltage and current caused by harmonics, power filter minimises the harmonic content in the ac low power factor etc. This may cause undesirable effects system, corrects the power factor at fundamental such as tripping of circuit breakers due to overload, frequency, regulates the voltage magnitude and balance overheating of distribution transformers, neutral heating loads.

due to triple $n$ harmonics, etc. Lack of standard quality power can cause damage of equipment or even be harmful to human health resulting in loss of production. Therefore in the recent years, focus has been given on improving "Electrical Power Quality" (EPQ) [1].

Harmonics are defined as sinusoidal waveforms having frequencies that are integral multiples of the power line frequency. It is an indication of the deviation of the actual voltage or current waveform from an ideal sinusoidal waveform. Usage of power electronics converter and inverter systems has given rise to an increase in the harmonics. However the solution to this problem is also provided by power electronics through usage of Active power filters (APF), Unified power quality conditioner (UPQC), etc.

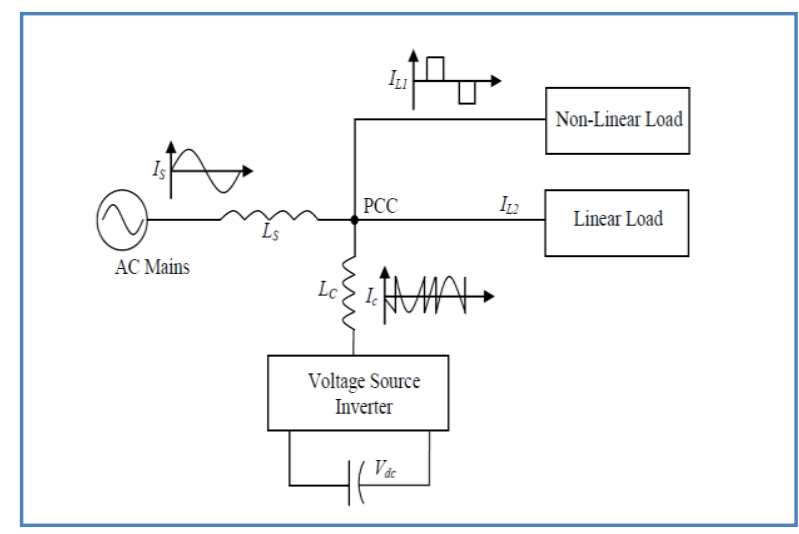

Figure 1: Basic Configuration of Shunt Active Power Filter 


\author{
National Conference on Advances in Electrical Engineering \\ NMAM Institute of Technology, Nitte \\ Vol. 5, Special Issue 2, April 2017
}

The paper is structured as follows. The reviews of only algebraic operations are required. The only exception harmonic detection method used in the paper are is in the separation of some power components in their addressed in section II. The reviews of gating signal mean and alternating values. The p-q theory consists of an generation method in section III. Performance indexes for algebraic transformation (Clarke transformation) of the the comparison are described in section IV. Finally, three-phase voltages and currents in the a-b-c coordinates section $\mathrm{V}$ is conclusion.

\title{
II. REFERENCE SIGNAL ESTIMATION TECHNIQUES
}

Many control methods are proposed in the literature to extract the reference currents from the distorted line currents. Classification according to reference current extraction techniques can be computed as time domain and frequency domain method. Frequency domain approaches are suitable for both single and three-phase systems. Time domain approaches are mainly used for three-phase systems. The first technique uses Fast Fourier Transform (FFT) to extract harmonics in frequency domain and the other technique mentioned in Fig 2. is to extract current harmonics in time domain. Fast Fourier Transform (FFT) method requires heavy calculations and requires a lot of memory where as other methods are based on the calculation of direct and indirect current components.

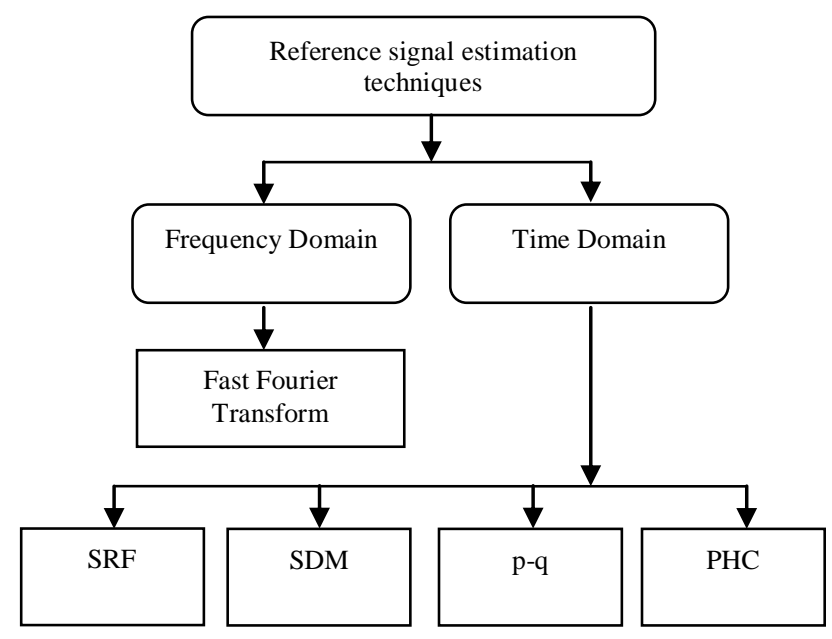

Figure 2: Shows Reference signal estimation techniques

The merit of time domain method is its fast response compared to frequency-domain hence this paper discuss time domain methods.

\section{A. Instantaneous Reactive Power or P-Q Theory}

In 1983, Akagi et al. [4-5] have proposed the Generalized Theory of the Instantaneous Reactive Power in ThreePhase Circuits, also known as p-q theory. It is based in instantaneous values in three-phase power systems, and is valid for steady-state or transitory operations, as well as for generic voltage and current waveforms, allowing the control of the active filters in real-time. Another advantage of this theory is the simplicity of its calculations, since to the $\alpha-\beta$ coordinates, followed by the calculation of the $\mathrm{p}-\mathrm{q}$ theory instantaneous active and reactive powers components [6-7]. This scheme is most widely used because of its fast dynamic response but gives inaccurate results under distorted and asymmetrical source conditions. p-q theory compensates the harmonic currents, corrects the power factor, compensates dynamically, and instantaneously, the zero-sequence current [2]. Also balances and reduces the values of the currents supplied by the source to the load. Since $p-q$ method is frequency variant, on providing additional PLL circuit it becomes frequency independent.

\section{B. Synchronous Reference Frame (SRF) Theory}

The synchronous reference frame theory also known as dq theory is based on time-domain reference signal estimation techniques. In this theory, the compensation signals are calculated based on a synchronously rotating reference frame. The synchronous reference frame theory or $\mathrm{d}$-q theory performs the operation in steady-state or transient state as well as for generic voltage and current waveforms. .The active power filters controlling is done in real-time system using d-q theory. SRF theory is used to extract the three-phase reference currents (ica*, icb*,icc*) used by the active power filters [2]. Another important characteristic of this theory is the simplicity of the calculations, which involves only algebraic calculation. Large numbers of synchronization problems with unbalanced and non sinusoidal voltages are also avoided because it is observed that instantaneous active and reactive current id-iq method always give better result under un-balanced and non-sinusoidal voltage conditions over the instantaneous active and reactive power $p-q$ method. It is found from study of various present techniques for reduction of current harmonic, SRF Theory is the best for both near load and non linear load and also for non regular source [3].

\section{Synchronous Detection Method (SDM)}

In SDM [8], it is assumed the source currents (isa, isb, isc) are balanced after compensation. Then the three-phase reactive powers are calculated from the source voltages. Then the three-phase source currents are calculated. Finally the reference currents are calculated for the active power filters Using SDM. But the performance $p-q$ theory is much faster than compensation using SDM. It is proved that $\mathrm{p}-\mathrm{q}$ theory compensates the undesirable current components within 1st cycle whereas SDM takes about 14 cycles (approximately 0:23 seconds for $50 \mathrm{~Hz}$ source) [9]. So for faster power quality improvement SDM is not preferable. 


\author{
National Conference on Advances in Electrical Engineering \\ NMAM Institute of Technology, Nitte \\ Vol. 5, Special Issue 2, April 2017
}

D. Perfect Harmonic Cancellation (PHC)

PHC strategy is capable of simultaneous mitigation of harmonics distortion, compensation of fundamental reactive power, and elimination of imbalance in source current. Therefore, the source current will be in phase with the fundamental positive sequence component of the voltage at PCC.[16-17]

\section{III.GATING SIGNAL GENERATION METHOD}

In active filter applications, the inverter delivers a current which compensates for harmonics and distortions absorbed by the load. The mostly used techniques for the generation of gating pulses are Pulse Width Modulation (PWM) and Hysteresis Current Control (HCC). The switching signals thus generated are fed to VSI with a DC link capacitor across it. Based on these switching signals the inverter generates compensating current in phase opposition to the line current.

Output Voltage of the Inverter can be modified or controlled by controlling or modifying switching current, or in case of Power Switches, by controlling or modifying Gate current. The compensating current is injected back into the power line at the PCC and thus suppressing the current harmonics present in the line [1]

\section{A. PWM Techniques}

These techniques are most efficient and they control the drives of the switching devices. We get a controlled or modified AC output voltage by varying the $\mathrm{ON}$ and $\mathrm{OFF}$ time of power switches of the inverter. This method is popularly called as Pulse Width Modulation (PWM) method. A fixed DC voltage is given to the inverter and power switches are controlled by this PWM control signal to modulate input $\mathrm{DC}$ voltage to required $\mathrm{AC}$ voltage. The power switch is usually of MOSFET or IGBT. Since frequency of operation is inversely dependent upon Inverter size so to reduce the Inverter size we have to increase the switching frequency.

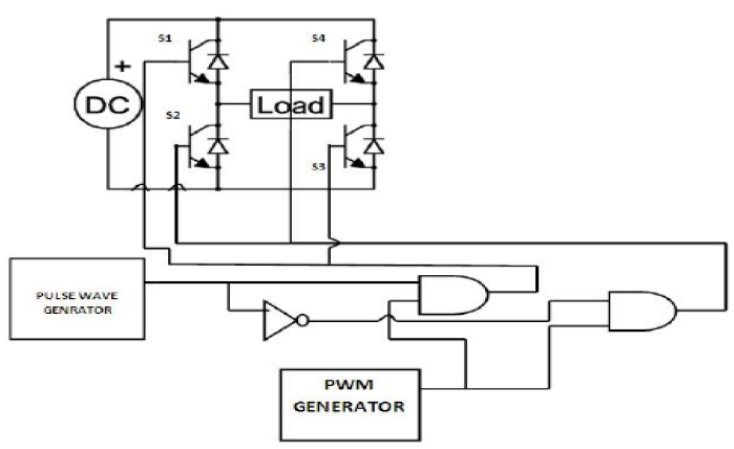

Figure 3: PWM Control of Inverter

The inverted rectangular waveform is logically ANDED with PWM waveform and is fed to power switches S2 and S4. Thus ON and OFF time of power switches are controlled by this PWM control signal. The power switch is usually of MOSFET or IGBT. The size of Inverter depends on size of these power switches.

\section{B. Hysteresis Current Controller}

The hysteresis band current control for active power filter is used to generate the switching pattern of the inverter. There are various current control methods proposed for active power filter configurations; but the hysteresis current control method is proven to be the best among other current control methods, because of quick current controllability, easy implementation unconditioned stability, fastest control with minimum hardware.

Fig 4 consists of a hysteresis band surrounding the generated, error current. The current error is obtained by subtracting the actual filter current from the reference current. The error signal is then fed to the relay with the desired hysteresis band to obtain the switching pulses for the inverter.

A band is set above and below the generated error signal. Whenever this signal crosses the upper band, the output voltage changes so as to decrease the input current and whenever the signal crosses the lower band, the output voltage changes to increase the input current. Accordingly switching signals are generated [5]. Hysteresis band current control has two modified techniques such as adaptive hysteresis current control and Dead-beat hysteresis current control for current-fed PWM converter. [18-20]

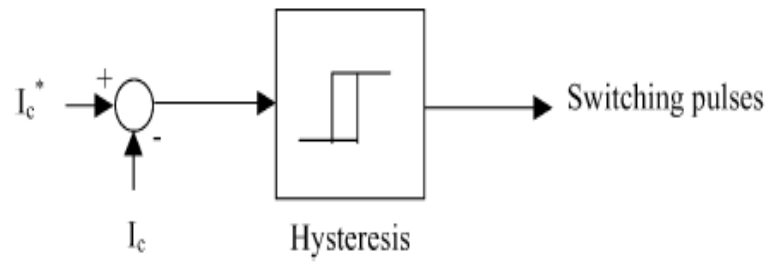

(a)

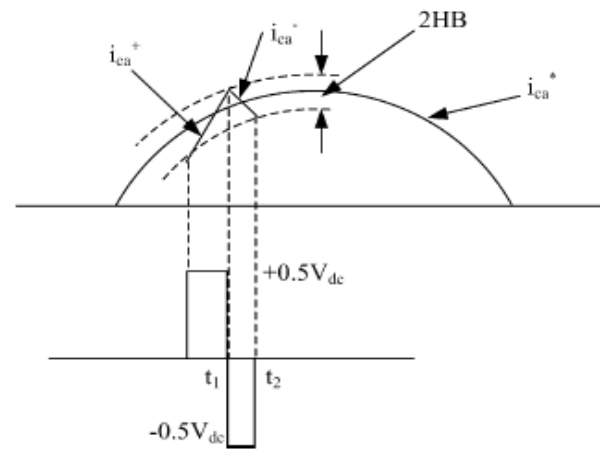

(b)

Figure 4:(a) Conventional hysteresis band current controller

(b) Current and voltage waves with hysteresis band current control.[20] 


\author{
National Conference on Advances in Electrical Engineering \\ NMAM Institute of Technology, Nitte \\ Vol. 5, Special Issue 2, April 2017
}

The method minimizes mutual interference among the controls of the various phases, while requiring only an approximate knowledge of passive load parameters. Moreover, PLL synchronization ensures constant frequency operation of the inverter switches.[21]

\section{Sliding Mode Controller}

The sliding mode control has characteristics such as fastness, robustness and stability for large load variations. The references for the sliding mode control system are obtained by using the instantaneous reactive power theory [11]. In sliding-mode controllers, either dc-bus voltage (in a VSI) or dc-bus current (in a CSI) is maintained to the desired value and reference values for the magnitudes of the supply currents are obtained. Subtracting load currents from reference supply currents, compensating commands are derived. Sliding-mode control technique uses the nonlinear control law shown in Table I
TABLE I

\begin{tabular}{|l|l|l|}
\hline Switch & is $<$ k vs & is $\geq$ k vs \\
\hline $\mathrm{i}$ & 0 & 1 \\
\hline ii & 1 & 0 \\
\hline Switch & vs $\leq \mathbf{0}$ & vs $>\mathbf{0}$ \\
\hline iii & 1 & 0 \\
\hline iv & 0 & 1 \\
\hline
\end{tabular}

Here, is source current, vs source voltage, $\mathrm{k}$ scaling factor and 0 -Low Level, 1 -High Level

\section{QUANTITATIVE MEASURE}

The relevant performance indexes will be characterized by the total harmonic distortion (THD) of the mains current, as mentioned in the Table II.

TABLE II Comparison of The Different Control Strategies

\begin{tabular}{|c|c|c|c|}
\hline $\begin{array}{l}\text { Compensation signal } \\
\text { Generation method }\end{array}$ & $\begin{array}{c}\text { Gating signal } \\
\text { generation method }\end{array}$ & THD & Remark \\
\hline SRF /d-q & PWM & $\begin{array}{l}2.27 \% \text { (under balanced } \\
\text { sinusoidal voltage) }\end{array}$ & \multirow{6}{*}{$\begin{array}{l}\text { three phase four wire system, } \\
\text { id-iq method lead } \\
\text { always better result under un- } \\
\text { balanced and non-sinusoidal } \\
\text { voltage conditions over p-q } \\
\text { method [12] }\end{array}$} \\
\hline SRF /d-q & PWM & $\begin{array}{l}5.18 \% \text { (under Un-balanced } \\
\text { sinusoidal voltage) }\end{array}$ & \\
\hline SRF /d-q & PWM & $\begin{array}{l}3.01 \% \text { (under balanced non } \\
\text { sinusoidal voltage) }\end{array}$ & \\
\hline $\mathrm{p}-\mathrm{q}$ & PWM & $\begin{array}{c}2.41 \% \text { (under balanced } \\
\text { sinusoidal voltage) }\end{array}$ & \\
\hline $\mathrm{p}-\mathrm{q}$ & PWM & $\begin{array}{c}7.04 \% \text { (under Un-balanced } \\
\text { sinusoidal voltage) }\end{array}$ & \\
\hline $\mathrm{p}-\mathrm{q}$ & PWM & $\begin{array}{l}9.07 \% \text { (under balanced non } \\
\text { sinusoidal voltage) }\end{array}$ & \\
\hline SRF / d-q & PWM & $\begin{array}{l}8.4 \% \text { (unbalanced load } \\
\text { current) }\end{array}$ & \multirow{3}{*}{$\begin{array}{l}\text { system has good dynamic } \\
\text { performance with Load } \\
\text { current }[13][14][15]\end{array}$} \\
\hline SRF / d-q & Double HCC & $1.0 \%$ & \\
\hline SRF / d-q & $\mathrm{HCC}$ & $2.82 \%$ & \\
\hline SRF / d-q & Dead-beat control & $\begin{array}{c}0.041 \% \text { (Ideal Mains } \\
\text { Voltage) }\end{array}$ & \multirow{8}{*}{$\begin{array}{l}\text { Switching losses are reduced } \\
\text { with dead beat control and } \\
\text { results demonstrate the } \\
\text { superior capability of PHC } \\
\text { strategy in reducing source } \\
\text { current distortion [6][16][17] }\end{array}$} \\
\hline SRF / d-q & Dead-beat control & $\begin{array}{c}4.23 \% \text { (Balanced and } \\
\text { Distorted Source Voltages) }\end{array}$ & \\
\hline $\mathrm{p}-\mathrm{q}$ & Dead-beat control & $\begin{array}{c}0.041 \% \text { (Ideal Mains } \\
\text { Voltage) }\end{array}$ & \\
\hline $\mathrm{p}-\mathrm{q}$ & Dead-beat control & $\begin{array}{c}25.79 \% \text { (Balanced and } \\
\text { Distorted Source Voltages) }\end{array}$ & \\
\hline PHC & Dead-beat control & $\begin{array}{c}0.044 \% \text { (Ideal Mains } \\
\text { Voltage) } \\
\end{array}$ & \\
\hline PHC & Dead-beat control & $\begin{array}{c}0.045 \% \text { (Balanced and } \\
\text { Distorted Source Voltages) }\end{array}$ & \\
\hline PHC & $\mathrm{HCC}$ & $\begin{array}{c}4.6 \% \text { (under heavy nonlinear } \\
\text { load) }\end{array}$ & \\
\hline SRF / d-q & Adaptive HCC & $4.48 \%$ & \\
\hline
\end{tabular}


NCAEE 2017

National Conference on Advances in Electrical Engineering

NMAM Institute of Technology, Nitte

Vol. 5, Special Issue 2, April 2017

\begin{tabular}{|c|c|c|l|}
\hline SRF / d-q & Sliding Mode & Less than 2\% & $\begin{array}{l}\text { Good regulation in DC bus } \\
\text { for load variation [11] }\end{array}$ \\
\hline SD & & $0.41 \%$ & $\begin{array}{l}\text { DQ method provides the } \\
\text { minimum \% THD after } \\
\text { compensation compared with } \\
\text { SD[8] }\end{array}$ \\
\hline
\end{tabular}

\section{CONCLUSION}

A brief review about the control strategies of ( $\mathrm{p}-\mathrm{q}$; $\mathrm{d}-\mathrm{q}$, SD and PHC) for active power filters have been made taking the THD as the quantitative measure. Among the four controllers, $\mathrm{p}-\mathrm{q}, \mathrm{SD}$ and $\mathrm{d}-\mathrm{q}$ strategies are the most sensitive to voltage distortion at PCC. The results show that the PHF method provides the minimum \% THD after compensation compared with other methods.

\section{REFERENCES}

[1] Arindam ghosh, Gerard Ledwich, "Power Quality Enhancement Using Custom Power Devices"

[2] Bhattacharya S. and Divan D., "Synchronous frame based controller implementation for a hybrid series active filter system", IEEE Conf. On Industry applications, vol.4,1995, 2531-2540.

[3] M. Suresh , S.S.Patnaik, Y. Suresh, Prof. A.K. Panda, "Comparison of Two Compensation Control Strategies for Shunt Active Power Filter in Three-Phase Four-Wire System", 2011 IEEE.

[4] Akagi, H., " New trends in active filters for improving power quality, in Proc. of the International Conference on Power Electronics",Drives and Energy Systems for Industrial Growth, 1996,Vol. 1, Issue 8-11, 417 - 425.

[5] H. Akagi, A. Nabae, and S. Atoh, "Control strategy of active power filters using multiple voltage-source PWM converters", IEEE Trans. Ind. Applicat, vol. IA-22,1986, pp. 460-165.

[6] María Isabel Milanés Montero, Enrique Romero Cadaval, and Fermín Barrero González, "Comparison of Control Strategies for Shunt Active Power Filters in Three-Phase Four-Wire Systems", IEEE transactions on Power Electronics, VOL. 22, NO. 1, January 2007.

[7] João L. Afonso, Member, IEEE, M. J. Sepúlveda Freitas, and Júlio S. Martins,Member,IEEE, "p-q Theory Power Components Calculations", ISIE'2003 - IEEE International Symposium on Industrial ElectronicsRio de Janeiro, Brasil, 9-11 Junho de 2003, ISBN: 0-7803-7912-8

[8] K-L. Areerak and K-N. Areerak., "The Comparison Study of Harmonic Detection Methods for Shunt Active Power Filters", World Academy of Science, Engineering and Technology ,2010

[9] Md. Ashfanoor Kabir and Upal Mahbub, " Synchronous Detection and Digital control of Shunt Active Power Filter in Power Quality Improvement",2011 IEEE

[10] J. Acosta, Student Member, IEEE, A. Gonza'lez, PhD, Member,IEEE and Z.R.Martfnez, "FPGA Based Control Scheme for Active Power Filter"'

[11] N. Mendalek, "Sliding Mode Control of Three-Phase Four-Wire Shunt Active Power Filter", CCECE/CCGEI May 5-7 2008 Niagara Falls. Canada

[12] M. Suresh 1, S.S.Patnaik2, Y. Suresh3, Prof. A.K. Panda4, "Comparison of Two Compensation Control Strategies for Shunt Active Power Filter in Three-Phase Four-Wire System"

[13] Zhong. Chen, Dehong. Xu,Department of Electrical Engineering, Zhejiang University, P. R China, "Design and Implementation of a DSP-Based Shunt Active Power Filter in Three-phase Four-Wire System"

[14] Zeliang Shu, Student Member, IEEE, Yuhua Guo, and Jisan Lian, "Steady-State and Dynamic Study of Active Power Filter With Efficient FPGA-Based Control Algorithm"
[15] Saswat Kumar Ram, 2Smruti Ranjan Prusty, 1Prabhat Kumar Barik, 1K.K. Mahapatra ,2B.D. Subudhi, "FPGA Implementation of Digital Controller for Active Power Line Conditioner using SRF Theory"

[16] Mahmoud Ranjbar, and Alireza Jaliliany, "Compensation Strategies for Shunt Active Power Filter in Single- and Three-Phase Systems: Different Formulation, Comparison and Evaluation", journal of electric power and energy conversion systems (jepecs) jepecs vol. 1 , no. 1 , pp. $37-45$, spring 2016 issn: $2345-4830$ print/2345-4733

[17] Mahmoud Ranjbar, Student Member, IEEE, Alireza Jalilian, Abbas Shoulaie, "DSP-Based Digital Control of a Single-Phase Shunt Active Power Filter underDistorted Voltage Source"

[18] L. Sonaglioni , "Predictive Digital Hysteresis Current Control"

[19] Simone Buso, Sandro Fasolo, Luigi Malesani, and Paolo Mattavelli, "A Dead-Beat Adaptive Hysteresis Current Control", IEEE Transactions On Industry Applications, Vol. 36, No. 4, July/August 2000

[20] Murat Kale, Engin Ozdemir, "An adaptive hysteresis band current controller for shunt active power filter"

21] Luigi Malesani, Paolo Tenti “A Novel Hysteresis Control Method for Current-Controlled Voltage-Source PWM Inverters with Constant Modulation Frequency", IEEE Transactions On Industry Applications, Vol. 26. No. I , Januaryifebruary 1990

[22] "IEEE Recommended Practices and Requirements for Harmonic Control in Electrical Power Systems", IEEE SM 519-1992

[23] Kishore Ramesh Badgujar, Pankaj A. Salunkhe, Tushar M. Patil, "Generation of a High Resolution Pulse Width Modulated Wave Using FPGA", IJCSN International Journal of Computer Science and Network, Volume 5, Issue 5, October 201 